\title{
Experimental Investigation of PCM Assisted Greenhouse Solar Dryer for Hibiscus Leaves
}

\author{
Purusothaman $\mathrm{M}^{1, *}$, Valarmathi $\mathrm{T} \mathrm{N}^{2}$, Matta Eswar Yadav ${ }^{3}$ \\ ${ }^{1}$ Research scholar, ${ }^{2}$ Associate Professor, ${ }^{3}$ Student, \\ School of Mechanical Engineering, \\ Sathyabama Institute of Science and Technology, Chennai-119, India.
}

\begin{abstract}
In this study, the experimental investigation of parabolic roof greenhouse solar dryer assisted with PCM chamber has been studied. The granular paraffin wax used as PCM for continuous drying process during cloudy and sunset hours. The parabolic roof green house solar dryer is developed with a dimension of $1.5 \mathrm{~m} \times 1 \mathrm{mx} 1.02 \mathrm{~m}$. The setup consists of a blower, solar collector, PCM storage chamber and a greenhouse drying chamber. The medium used for forced convection is air and it is circulated throughout the setup using the insulated copper tubes. The PCM store the latent heat energy during solar hours and releases during sunset hours. The thermal behaviour of energy storage system is evaluated during charging and discharging process. The maximum temperature attained by PCM during charging is $56.6^{\circ} \mathrm{C}$ within 5 hours and minimum temperature attained by PCM during discharging is $37.6^{\circ} \mathrm{C}$ by using air as heat transfer fluid. The performance of the dryer assessed by with PCM assisted, without PCM and open drying. The use of latent heat storage for drying and the quality of the drying material is assessed and compared to open drying. Results concluded that, dryer with PCM took only 11 hours, whereas 14 hours without PCM and 16 hours for open drying. Nutrition test results also reveal that all the elements of nutrition are more than the other drying modes.
\end{abstract}

Keywords: Greenhouse solar dryer, PCM, Polyethylene, Hibiscus Leaves.

\section{INTRODUCTION}

World were facing the problem of energy crisis because of a huge demand between the energy source and energy demand, it can be minimised by using renewable energy sources. Effects of using PCM and honeycomb type solar based air heater are studied with PCM and as internal fine structure [10]. Performance is carried out for 6 different air flow rates over a range of 0.008 to 0.048 $\mathrm{kg} / \mathrm{second}$. Heat storage materials were tested in different forms as results, heaters with PCM has more efficient between 2.6 to $22.3 \%$ at higher mass flow rates. Benzoic and stearic are two LH storage materials and palm olefin is SH storage material were selected to analyse the annular storage with cavity and transient condition thermal analysis is done by using ANASYS 16.0[1]. As STES system sustained at a temperature of 60 and $50^{\circ} \mathrm{C}$ for 1 and $1.5 \mathrm{~kg}$ of water for $200 \mathrm{~min}$, shows that annular cavity storage for lower temperature application is suitable. Heat dissipation process is enhanced by combining solar energy receiving heat storage units with phase change materials. Heat storage units are analysed for temperature distribution at different solar radiation flux and elevation angle. At $60^{\circ}$ elevation angle, heat storage capacity is higher and rate of
STHSE were achieved. $97 \%$ of overall efficiency is achieved for heat dissipation [22].

The energy produce during the peak time is stored and using it during non sunshine hours is carried out by using solar system. Solar drying is used for the purpose of drying agricultural food products. A PCM is also added in order to increase the efficiency of the solar dryer, which dries agricultural food products [9]. Review on solar drying is given by considering the parameters which affects the operation of solar dryer along with advantages, disadvantages and limitations. Amount of $6400 \mathrm{~kg} /$ month of $\mathrm{CO}_{2}$ emission is decreased where pressure is equals to 0.6 and which dries $120 \mathrm{~kg}$ of carrot [8]. Quality and uniformity are dependent parameters during the solar drying process where uniformity is affected by air properties and it can be improved by integrating dehumidification system. To enhance solar drying process, quality and uniformity are increased by modulating some of the parameters which influence on its [18].In food industry, drying of food products will plays a major where best method for drying is solar dryers. In order to increase the efficiency of solar dryer, double uses of solar collector are used with providing consumptive hot water [2].

Experimental analysis is carried by thermal lag of PCM for dual pass solar air heating unit. Investigation is carried out whether discrete unit allows quicker charging and slower discharging of PCM. The average encapsulated efficiency of DPSAHS is $47.21 \%$ and $67 \%$ obtained for rectangular as well as cylindrical encapsulate. By using these systems marginal and subsistent farmer will deal with proper drying during winter seasons [16]. Thermodynamics perspective, there is extensive exploitation for solar energy. So, the energy as well as exergy analyses are carried out for different solar energy system [19]. Drying is a good alternate than frozen of food products in terms of economic and complexity. PCM is an application in solar energy storage system. By using PCM the efficiency of the system increases and which it can withstand the temperature higher than $62^{\circ} \mathrm{C}$ where PCM based driers are used for fish drying. $\mathrm{Mu}$ Song et al. gave us the insights about Solar drying by the principle of LH Storage. This drying method is formulated in order to resolve the problems of continuity of solar drying. This system is mainly developed for drying grapes as it is the most critical operation in the making of raisins [21]. Generally, the drying process is carried out in the open or natural air-drying shelter. These methods take longer time for drying. In recent years most of the research has been done to develop drying system using solar drying 
technology. The results in the experiment were encouraging as the characteristics of solar dryer and performance of solar with LH storage system are on par with the desired value.

The properties of the paraffin wax used to increasing efficiency of the solar energy storage systems. This work concerns the modelling and numerical analysis of PCM melting in the storage system of solar energy. The PCM is transfers the heat coming from a solar collector and circulating in to the duct. Initially, the heat transfer is dominated by conduction. Thus, the melting front moves away uniformly and next the natural convection develops. After 480 minutes the natural convection is fully developed and is responsible for the rapid melting. The complete melting is observed after 720 minutes. This gave us the insights about using paraffin wax and increasing its thermal efficiency [7]. Studied about different heat storage systems and applications for sustainable development. Since solar energy is important source of energy which is responsible for other renewable sources directly or indirectly. It gave us insights about effective utilization of phase change materials and their thermal energy storage [6].

Review focus on three important features like materials, encapsulation and application of organic PCM. Organic PCM have low thermal conductivity value hence a more surface area is needed to increase the transfer rate. Since Organic PCM is ideal, the characteristics and properties are considered to choose an ideal PCM to store the energy. During phase change the temperature, high specific heat, high latent heat and high thermal conductivity in liquid as well as solid properties are studied. The physical properties such as high density, no sub-cooling, low vapour pressure and small volume change. Also it should be abundantly available and should not be expensive [17]. Investigated solar dryer assisted with PCM have been done for drying. This study helps in collecting the data and inferring the results in an area where the sun is not present for the most part of the year and see whether the latent heat storage system. Their Analysis shows that using the phase change material, drying time reduced by $38 \%$ and $64.29 \%$ as compared drying with heat pump and traditional shade drying, respectively. Use of PCM led to higher drying rate and superior quality is observed in the material dried. The aim of optimization is to find the quantity PCM, number of channels, aspect ratio and rate of flow through the solar collector to maximize heat storage efficiency [4]. Proposed Octadecane-lauric acid/expanded graphite shape-stabilized PCM, which is suitable to heat storage for solar greenhouse production, were prepared by using the eutectic mixture of octadecane and lauric acid as PCM, porous expanded graphite of high adsorption characteristics as supporting matrix [5]. Investigates the performance of a single basin double slope solar still in conjunction with a thermal energy storage material: paraffin wax as a heat reservoir under the liner of the basin. The heat transfer coefficients have been evaluated and the variations trend is studied. The daily experimental uncertainty was approximated to $16 \%$. An experimental work has been performed on the solar still equipped with phase change material. Overall $61 \%$ gain was observed when paraffin wax was used in solar still, whereas a $34 \%$ nocturnal and $64 \%$ gain in a day time distillate was recorded [3]. The greenhouse solar dryer analysis by using CFD. The maximum temperature is obtained in forced convection as $71{ }^{\circ} \mathrm{C}$ for $0.025 \mathrm{~kg} / \mathrm{s}$ mass flow rate which is $41 \%$ higher than the natural convection [12],[13] and different PCM analysis with CFD are made by the researcher[14],[15]. Review study on recent development in the drying of food products to give the direction to the young researcher to understand the recent methods, products, and optimization [20]. The novelty of the current research work to develop a better greenhouse even span roof solar dryer with PCM assisted to perform the experimentations for hibiscus leaves drying. Temperature, humidity, weight moisture content and nutrition analysis of the product has been studied using this dryer.

\section{MATERIALS AND METHODOLOGY}

Materials used in this article with its methodology to drive the work are given below with comparing with other process.

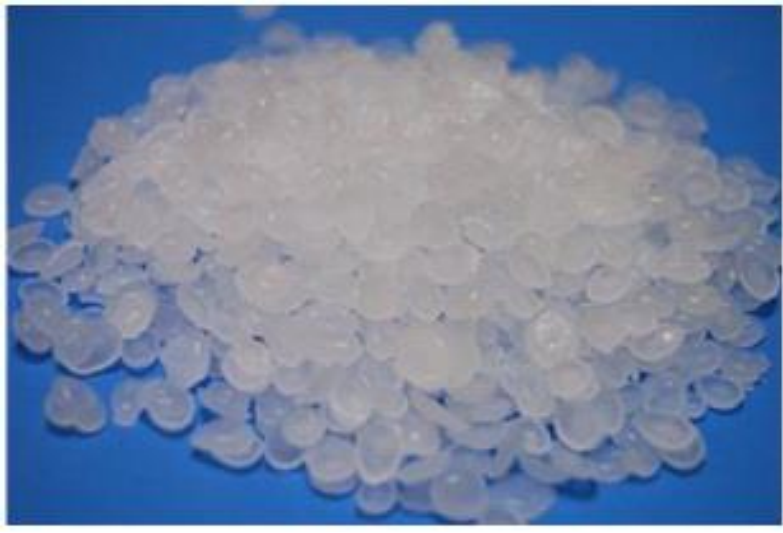

Fig.1 Granular paraffin wax.

Paraffin wax material is used as Phase Change Material, which can absorbs heat during charging process where the heat is stored as latent heat by changing the phase from solid to liquid and it will release while discharging process which converts into solid from liquid by releasing the energy in the form latent heat. The properties of PCM are given in Table.1 and The organic granular paraffin wax PCM sample as shown in Fig.1.The drying product selected for this experiment is Hibiscus leaves shown in Fig.2. Hibiscus leaves dried separately in drying chamber and under the open sun in order to compare the drying efficiency and quality of drying.

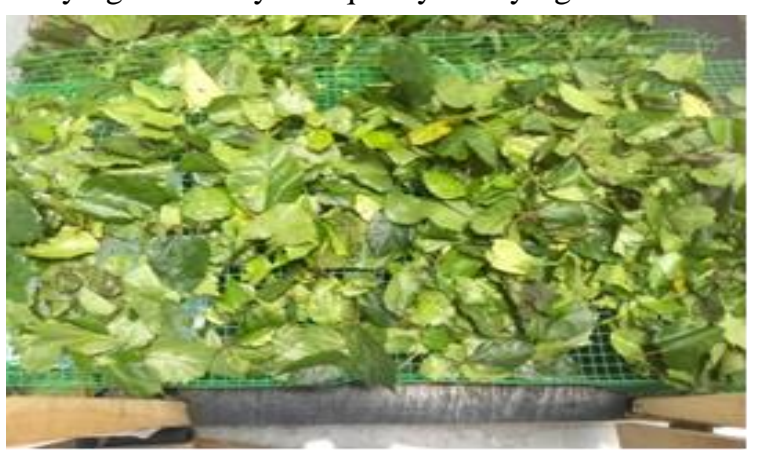

Fig.2 Hibiscus Leaves sample 
Hibiscus tea, also called sour tea because of its tart taste, is made from a mixture of dried hibiscus flowers, leaves, and dark red calyces (the cup-shaped centres of the flowers). It is used to decrease the body temperature, to treat heart and nerve diseases, and as a diuretic in order to increase urine production.

\section{EXPERIMENTAL SETUP}

Air blower is connected to the copper tubes inside the solar collector. And the outlet of solar collector is connected to the PCM chamber with connecting tube of diameter $1 \mathrm{~cm}$ made of copper. The copper tube is connected to the inlet of PCM chamber. Then the PCM chamber outlet is connected to the drying chamber in which the hibiscus leaves are placed shown in Fig.3.

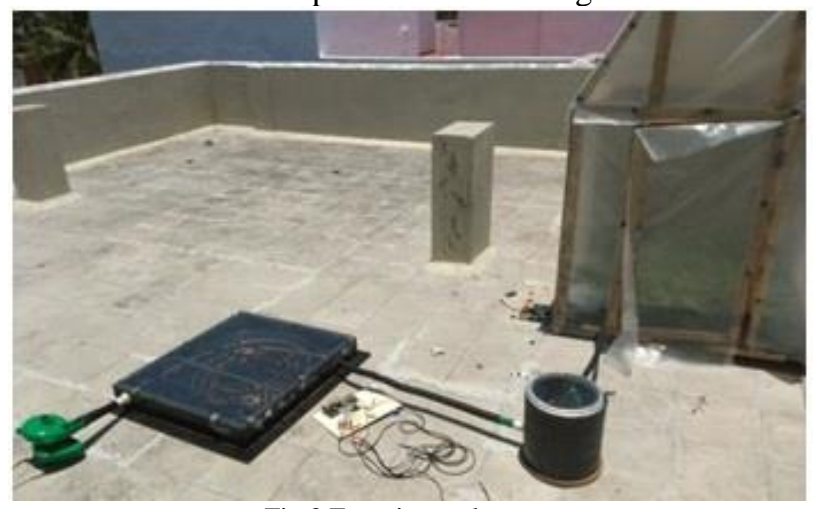

Fig.3 Experimental setup.

The experiment has been conducted on Hibiscus leaves. $500 \mathrm{~g}$ of Hibiscus leaves are taken in drying chamber for greenhouse solar drying. 500g of another sample of Hibiscus leaves are placed outside for open sun drying. The leaves in the drying chamber are placed on a tray so that that hot air coming out from PCM chamber can be supplied from the bottom of the leaves.

The experiment has started at the time morning 11:00Am. The blower has started running and it will take ambient air and the air will be sent to the solar collector through copper tubes. Now the air will be circulated copper tubes inside the solar collector and it will get heated due to the solar radiation absorbed by the absorber plate. The hot air will be sent to the PCM chamber which is connected by a copper tube. The hot air will circulate through the aluminium coils in the PCM chamber. Due to the heat dissipation of hot air through aluminium coil the Paraffin wax inside the PCM chamber will get heated. And the heat absorbed by paraffin will store as the latent heat storage in it during charging time. After coming out from the PCM chamber the air temperature will be reduced and this air will be sent to the drying chamber so that the remaining het can be utilized to dry the drying product. And this air will be removed out from drying chamber by using an exhaust fan.

But during the sunset hours and night time the solar radiation will be very less and air coming into the PCM chamber will have less temperature than the temperature of Paraffin wax in PCM chamber. So now the discharging time will starts where Paraffin wax will dissipate heat and the air flowing into the drying chamber will get heated. And the drying process will be continues during the night time also. The temperatures of PCM and air are noted by using a digital thermometer. The humidity in the drying chamber is measured by using a digital humidity meter. The solar drying product is measured on hour basis by using weight measuring device.

\section{RESULTS AND DISCUSSION}

The analysis is carried out by charging and discharging of PCM over a period of duration.

A. Charging and Discharging Time

The variation of temperatures of paraffin wax with during the charging time is shown in Fig.4. The temperature of paraffin wax reaches $56.6^{\circ} \mathrm{C}$ in first 5 hours of charging. The temperature increases rapidly in first 2 hours up to the temperature of $52.5^{\circ} \mathrm{C}$ and after that the changes in temperatures of PCM are very slow. The maximum temperature attained by Paraffin wax is $56.6^{\circ} \mathrm{C}$.

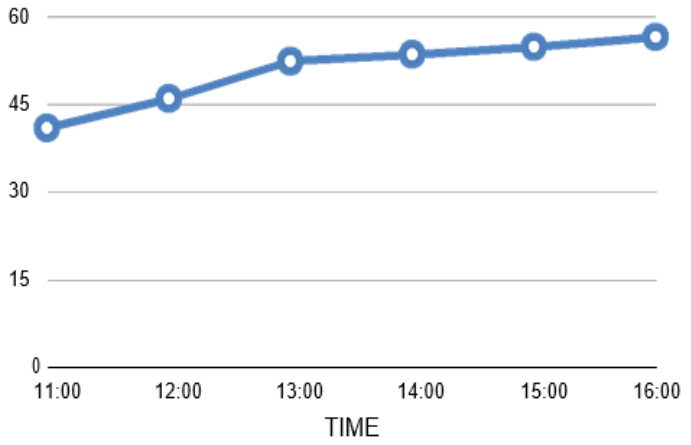

Fig.4 Charging Trend

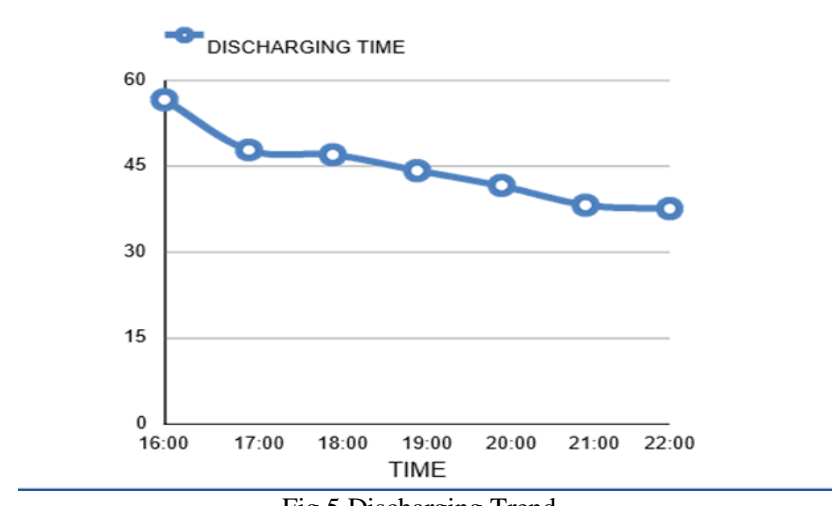

Fig.5 Discharging Trend.

The variations of temperatures of paraffin wax during the discharging are shown in Fig.5. The discharging of Paraffin starts during sun set hours at 5:00PM. The temperature drop starts from $56.6^{\circ} \mathrm{C}$. The drop in temperature of paraffin at the start of discharging is very low. But in the last 3 hours of discharging the temperature drops very quickly. And the minimum temperature attained by paraffin is $37.6^{\circ} \mathrm{C}$. 
B. Variation of Weight of the Product with the Drying Time

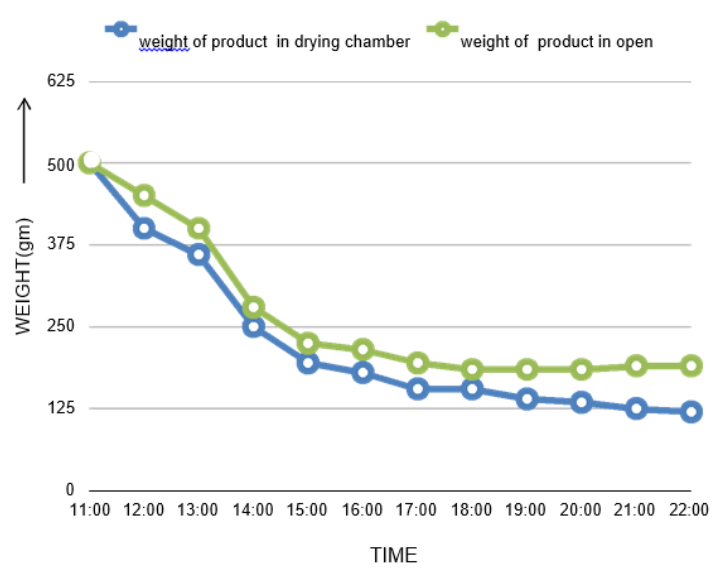

Fig.6. Reduction of weight.

Fig.6. shows the variation of weight of Hibiscus leaves with the time inside the drying chamber with forced convection and outside the drying chamber with open sun drying. The initial weight of the drying product is $500 \mathrm{~g}$. After the drying inside the drying chamber the weight of the Hibiscus leaves is reduced to $120 \mathrm{~g}$ in 11 hours and the initial weight of the Hibiscus leaves drying outside is $500 \mathrm{~g}$ and its weight is reduced to $180 \mathrm{~g}$ in same 11 hours.

C. Variation of Temperature with Drying Time

Fig.7. shows the variation of temperature of paraffin wax and variation of temperature inside the drying chamber with drying time. It can be observed that the temperature inside the drying chamber is always maintained above the atmospheric temperature. Generally the temp rapture inside the drying chamber during night time should be reduced due to the low solar radiation. But the temperature inside the drying chamber is maintained above the ambient temperature. It is because of the latent heat stored in the PCM material. During daytime the temperature of $\mathrm{PCM}$ is raised from $35^{\circ} \mathrm{c}$ to $56^{\circ} \mathrm{c}$ in 6 hours. It is the charging time of PCM. And the temperature of $\mathrm{PCM}$ is reduced to $37.6^{\circ} \mathrm{c}$ from $56^{\circ} \mathrm{c}$ in $5 \mathrm{hrs}$. It is the discharging time of PCM.

The temperature inside the drying chamber is always maintained high throughout day, during the night time also. It is because of the heat dissipated by PCM during discharging time. The maximum temperature attained inside the drying chamber is $43.2^{\circ} \mathrm{c}$. The lowest temperature maintained in the drying chamber is $32.6^{\circ} \mathrm{c}$.

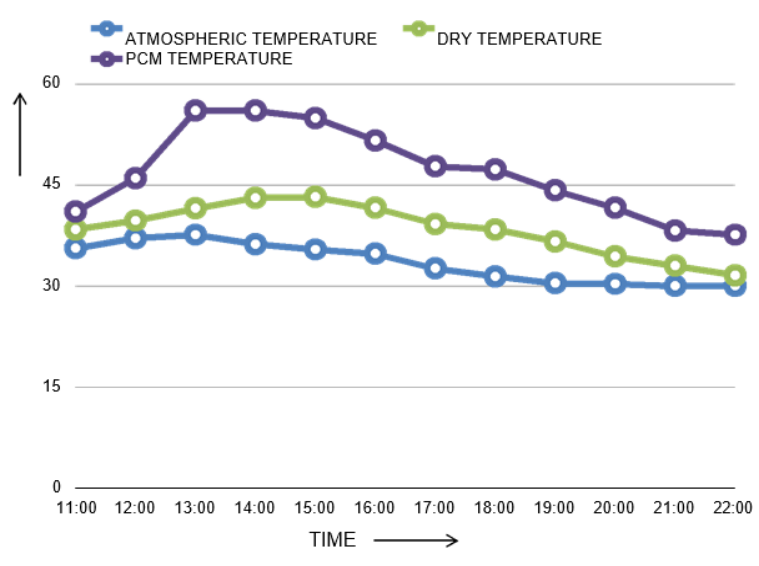

Fig.7. Variation of Temperature

\section{Variation of Humidity with Drying Time}

Fig.8.shows the variation of humidity in drying chamber with the drying time and compared with the ambient humidity. The humidity in atmosphere reaches above $85 \%$ during night time but the relative humidity inside the drying chamber reaches the maximum value of $64 \%$ only.

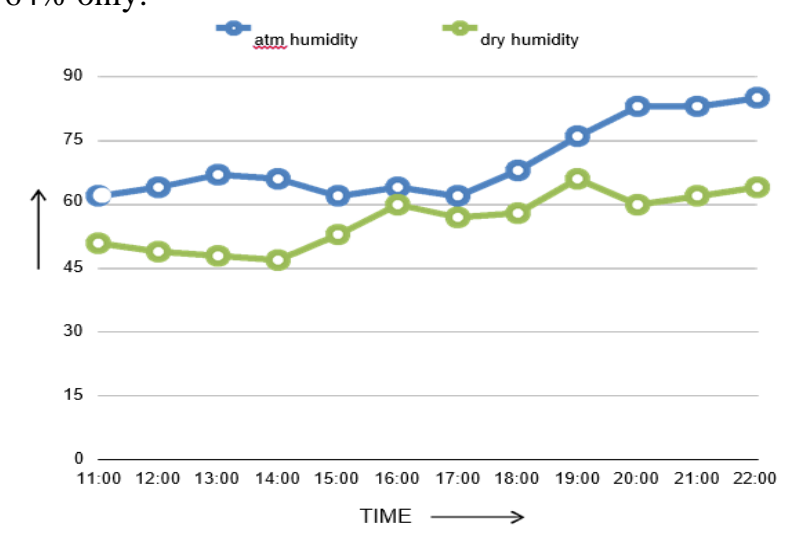

Fig.8. Variation of Humidity

\section{E. Variation of Air Temperature with Drying Time}

The variation of air temperature at inlet and outlet of the PCM chamber with drying time as shown in Fig.9. During the charging time of the PCM the inlet temperature of air is greater than the outlet temperature of air. During the discharging time of PCM the outlet temperature of air is greater than the inlet temperature of air. The maximum temperature difference between the outlet temperature of air and inlet temperature obtained during the charging process is $5.1^{\circ} \mathrm{c}$ and the maximum temperature difference obtained during the discharging process is $5.7^{\circ} \mathrm{C}$. 


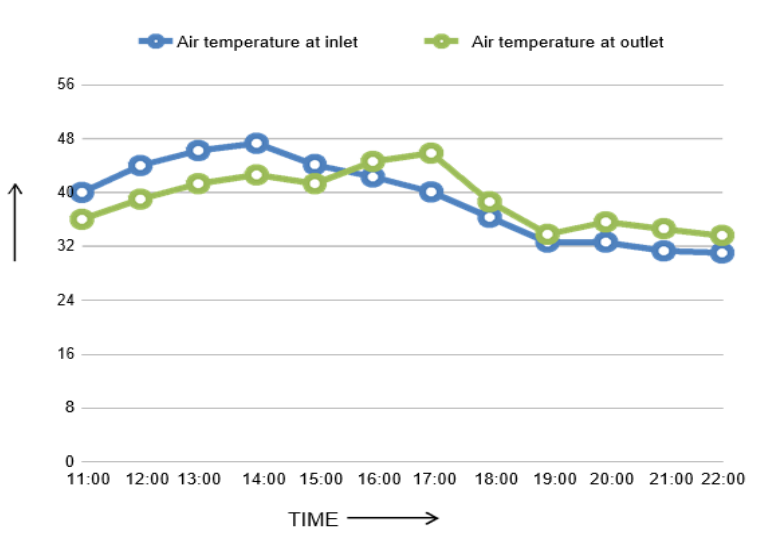

Fig.9. Variation of Air temperature

\section{F. Variation of Moisture Content with Drying Time}

Fig.10. shows the variation of moisture content (Wet basis) of Hibiscus leaves inside the drying chamber and open sun drying with the drying time. The drying product took $10 \mathrm{hrs}$ to reach the moisture content of $4.09 \%$ which is minimum for hibiscus leaves drying inside the drying chamber. The moisture content at the start of drying is $76 \%$. The moisture content of hibiscus leaves drying openly reduced to $38 \%$ in the same 10 hours which is higher than the leaves drying inside the drying chamber. The product drying openly took almost 5hrs extra for achieving minimum level of moisture content.

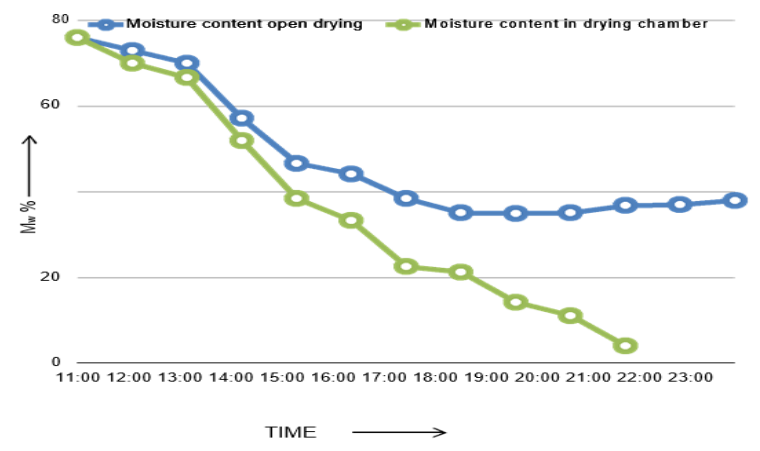

Fig.10. Reduction of moisture content

\section{G. Nutrition Analysis of Hibiscus Leaves}

The Hibiscus leaves are given for nutrition analysis before and after the drying process. Totally 3 samples are given for analysis. The samples tested for their nutrition parameters like Moisture, Protein, Crude fibre, Total Ash, Acid insoluble Ash, fat, Energy, Carbohydrates. From the analysis it is observed that all the parameters are high for the Hibiscus leaves dried in drying chamber. Moisture content is reduced to $10.53 \%$ in drying chamber and $21.96 \%$ in outside drying from $81.02 \%$. The energy levels are more in drying chamber than outside drying. And all the parameters increased after drying. The carbohydrate levels increased from $12.46 \%$ to $57.69 \%$. The nutrition elements of hibiscus leave sample before and after drying as shown in Fig.11. The comparison of energy levels for different samples as shown in Fig.12.

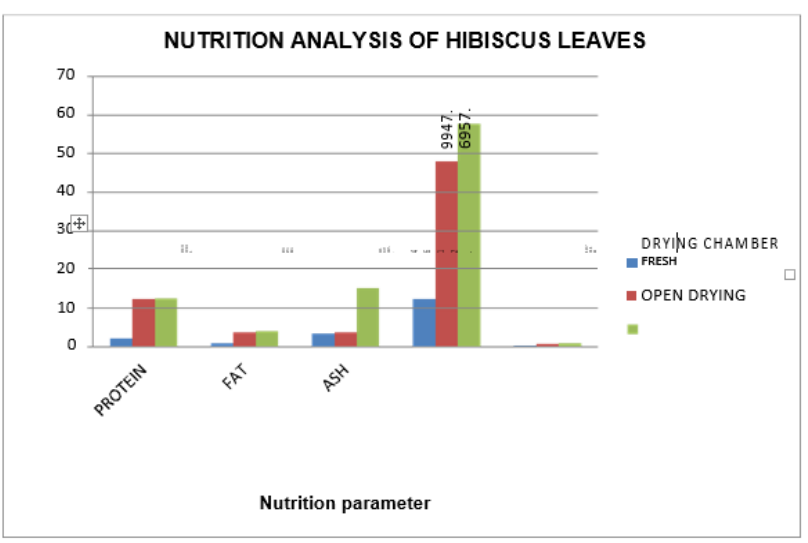

Fig.11 Nutrition analysis of Hibiscus Leaves.

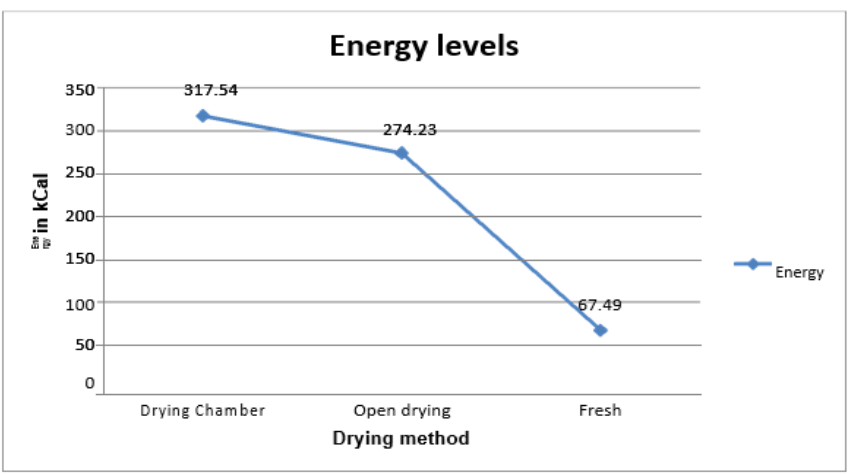

Fig.12 Energy of hibiscus with different drying methods

\section{CONCLUSION}

Experimental investigations have been carried to dry the hibiscus leaves and the following outcomes arrived from the experiments.

$>$ When compared to the open drying process, using the latent heat storage system is more advantageous as it can be used to dry the hibiscus leaves during the sunset hours.

$>$ The quality of the hibiscus leaves is higher when compared to the open drying.

$>$ The PCM discharging time is also higher and more than sufficient for dying the hibiscus leaves and it can be successfully used for bigger applications.

$>$ Higher drying rate and efficiencies are achieved. The drying period is less for almost five hours when compared to other types of drying.

$>$ The Nutrition test value reveals that compared to open drying the PCM assisted dryer is higher value in all respects.

\section{REFERENCES}

[1] Adetifa B O, Aremu A K., Computational and experimental study of solar thermal energy store for low temperature application, Journal of Energy Storage, Vol.20, pp.427-438.(2018)

[2] Alireza Mohajer, Omid Nematollahi, Mahmood Mastami Joybari, Seyed Ashmed Hashemi, Mohammad Reza Assari, Experimental investigation of a Hybrid Solar Driers and water heater system, Energy Conversion and Management, Vol.76, pp.935-944.(2013).

[3] Ashish Kumar,Ajeet Kumar Rai Drying of mint leaves in solar dryer and under open sun:modelling, performance analyses. Energy Conversation. Manage. 51, 2407-2418(2005).

[4] Bharadwaj A.k Energy and exergy analysis of different solar air collector systems with natural convection. Renewable Energy 74, 357-368(2009).

[5] Chien Minghui, Cheng Liyuan . Energy and exergy analysis of thin layer drying of coroba slices. J. Food Eng. 86, 151161(2008) 
[6] Dwivedi V.K. PrabhakarTiwari and SumitTiwari's solar engineering of thermal process,Apply energy 203(2001).

[7] Elbahjaoui.R and H. El Qarnia storage system for solar air heating applications. Sol. Energy 88,213-156(2002).

[8] Hisham Elhage, Amal Herez, Mohamad Ramadan, Hasan Bazzi, Mahmoud Khaled, An investigation on solar drying: A review with economic and environmental assessment, Energy, Vol.18. (2018).

[9] Lailt M. Bal, Santosh Satya, S.N. Naik, Venkatesh Meda, Review of solar dryers with latent heat storage systems for agricultural products, Renewable and Sustainable Energy Reviews, Vol.15, pp.876-880. (2011)

[10] Mesut Abuşka, Seyfi Șevik, Arif Kayapunar,. A comparative investigation of the effect of honey comb core on the latent heat storage with PCM in solar air heater, Applied Thermal Engineering, Vol.148, pp.684-693.(2019).

[11] Mu Song, Yi Songlin, Zhang Biguang, Mushrooms dehydration in a hybrid solar dryer, using a phase change material. Energy Conversion and Management (2012)

[12] Purusothaman M, Valarmathi T N, Computational Fluid Dynamics Analysis of Greenhouse Solar Dryer, International Journal of Ambient Energy, DOI:10.1080/01430750.2018.1437567.(2018).

[13] Purusothaman M, Valarmathi T N, Santhosh, Potnuru. (2019). CFD Analysis of Greenhouse Solar Dryer with Different Roof Shapes. $\quad$ IEEE, pp.408-412. Doi.10.1109/ICONSTEM.2019.8918788

[14] Purusothaman, M., kota, S., Sam Cornilius, C., \& Siva, R. (2017). Experimental Investigation of Thermal Performance in a Vehicle Cabin Test Setup With Pcm in the Roof. IOP Conference Series: Materials Science and Engineering, 197, 012073.doi:10.1088/1757-899x/197/1/012073.

[15] Purusothaman M ,Valarmathi T N,Dada Mohammad S K, Computational Fluid Dynamic Analysis of Enhancing Passenger
Cabin Comfort Using PCM, IOP Conf. Series: Materials Science and Engineering 149 (2016) 012197, doi:10.1088/1757 899X/149/1/012197.

[16] Raj A K, Srinivas M, ayaraj S, A cost-effective method to improve the performance of solar air heaters using discrete macro-encapsulated PCM capsules for drying applications,Applied Thermal Engineering, Vol.146, pp.910 920.(2019)

[17] Sharma R K , P Ganesan, V.V Tyagi, H.S.C Metselaar Latent heat storage materials and systems: a review. Int J Green Energy. ;2:156(2005).

[18] Shaymaa Husham Abdulmalek, Morteza Khalaji Assadi, Hussain H. Al-Kayiem, Ali Ahmed Gitan.. A Comparative analysis on the Uniformity Enhancement Methods of Solar Thermal Drying,Energy, S0360-5442(18)30071-9.(2018).

[19] Sunil Kumar Sansaniwal, Vashimant Sharma, Jyotirmay Mathur. Energy and exergy analyses of various typical solar energy applications: A comprehensive review. Applied Thermal Engineering. Vol 82, No. 2, 2017, pp 1576-1601.(2017).

[20] Valarmathi T N, Sekar S, Purushothaman M, Sekar S D, Maddela Rama Sharath Reddy and Kancham Reddy Naveen Kumar Reddy,(2017).Recent developments in drying of food products IOP Conference Series: Materials Science and Engineering, Vol.197,No.1,pp1-10.(2018)

[21] Virbhadra M. Swami, Arun T. Autee, Anil T R., Experimental analysis of solar fish dryer using phase change material,Journal of Energy Storage, Vol.20, pp.310-315. (2018).

[22] Yuchen Baia, Xiufen Hea, Yang Liu, Jianguo Duan, Yaxiong Wanga, Xiaoxing Hana, Experimental investigation of a solar thermal storage heater assembled with finned heat pipe an collective vacuum tubes, Energy Conversion and Management, Vol.166,pp.463-473. (2018) 